\title{
Label-Free Detection of Botulinum Neurotoxins Using a Surface Plasmon Resonance Biosensor
}

\author{
Hung Tran and Chun-Qiang Liu \\ Human Protection and Performance Division, \\ Defence Science and Technology Organisation, \\ Australia
}

\section{Introduction}

Neurotoxins produced by the Clostridium genus are the cause of botulism, a neuroparalytic disease (Dembek et al., 2007). Besides Clostridium botulinum, strains of other species such as Clostridium argentinense, Clostridium baratii and Clostridium butyricum can also produce botulinum neurotoxins (BoNTs) (Aureli et al., 1986; Hall et al., 1985). BoNTs are a complex containing the neurotoxin itself (molecular weight of $150 \mathrm{kDa}$ ) and its associated non-toxic proteins (Cai et al., 1999; Inoue et al., 1996). After synthesis, BoNTs are activated by a protease, forming a di-chain molecule consisting of a heavy chain (HC) $(100 \mathrm{kDa})$ and a light chain (LC) (50 kDa) linked by a disulfide bond (Singh, 2000). At its C-terminus, the HC binds to the presynaptic membrane through gangliosides and a protein receptor (Cai et al., 2007). The toxin is then internalised by endocytosis whereby the HC N-terminus aids the translocation of the LC into the cell cytoplasm (Montecucco \& Molgo, 2005; Simpson, 2004; Singh, 2006). The internalised LC is then able to block the release of acetylcholine by inhibiting the fusion of synaptic vesicles with the plasma membrane (Montecucco \& Molgo, 2005; Simpson, 2004; Singh, 2006; Singh, 2000). This is done by cleaving and thereby inactivating the enzymes that carry out the fusion of synaptic vesicles.

BoNTs are the most potent biological toxin known (Arnon et al., 2001; Gill, 1982). There are seven BoNT serotypes, A through $\mathrm{G}$, which are structurally related but antigenically different proteins (Dembek et al., 2007; Wictome et al., 1999). Botulinum neurotoxin A (BoNT/A) is the most potent of the seven serotypes (Poras et al., 2009). For example, just one gram of BoNT/A crystalline toxin, when evenly dispersed and inhaled, would kill more than one million people (Arnon et al., 2001; Hicks et al., 2005). From extrapolation of animal studies, an estimated human dose (assuming a 70-kg person) of BoNT/A that is lethal to $50 \%$ (LD50) of a population exposed is approximately 0.09 to $0.15 \mu \mathrm{g}$ intravenously or intramuscularly, 0.70 to $0.90 \mu \mathrm{g}$ by inhalation and $70 \mu \mathrm{g}$ orally (Gill, 1982; Schantz \& Johnson, 1992; Scott \& Suzuki, 1988). There are no currently licensed vaccines available to prevent botulism. An investigational vaccine, pentavalent botulinum toxoid (PBT), is accessible only to people who are deemed to be at high-risk, such as laboratory workers and military personnel (Bossi et al., 2004).

The extreme potency and lethality, the ease of distribution, and the need for prolonged intensive care among affected individuals make BoNTs ideal bioterror agents and 
bioweapon threats. A deliberate release of BoNTs in a civilian population may originate from a point-source aerosol release or contamination of a food supply. If successful, such bioterrorist attack would very likely overwhelm the existing public health system (Dembek et al., 2007), leading to public fear and social unrest (Cai et al., 2007). As a result, the US Centers for Disease Control and Prevention (CDC) has classified BoNTs as one of the six highest risk threat agents (Category A agent) for bioterrorism (Arnon et al., 2001). Like many other biological threats, rapid detection of BoNTs, in particular in the environment, food and/or clinical samples, is crucial not only to aid in early supportive care for those affected, but also as the key in minimising and managing the impact of a bioterrorism attack involving such potent toxins.

Currently, the mouse bioassay is the widely accepted standard and approved test for laboratory confirmation of botulism (Barr et al., 2005; Ferreira et al., 2003; Kautter \& Solomon, 1977; Sharma et al., 2006; Sugiyama, 1980). In this assay, mice after being given suspected BoNT samples were observed for symptoms of botulism for a period up to four days (Barr et al., 2005; Kulagina et al., 2007). Although sensitive, the mouse bioassay is cumbersome, time-consuming and expensive, and it also presents an ethical dilemma due to the use of large numbers of laboratory animals (Lindstrom \& Korkeala, 2006; Varnum et al., 2006). As a result, there has been a concerted effort over the last few decades to develop alternative detection methods, some of which have surpassed the detection limit of the mouse bioassay (Lindstrom \& Korkeala, 2006). The majority of these alternative assays are immunoassays, and the specificity and sensitivity of the assays are greatly dependent on the quality of the antibodies used.

In this chapter, we describe the development of a new immunoassay based on a surface plasmon resonance (SPR) biosensor for the detection of botulinum toxin serotypes A and B, using formalin-inactivated toxoids (BoTds). We demonstrate that the SPR assay does not cross-react with other closely-related BoTds, and is able to detect BoTds in environmental aerosol samples.

\section{Surface Plasmon Resonance technology}

Surface plasmon resonance (SPR) is a biophysical method that monitors real-time biomolecular interaction of two interacting molecules (often named ligand and analyte). Besides real time detection, SPR technology is also able to offer kinetic parameters of the measured biomolecular interaction. It allows the direct determination of separate association $\left(\mathrm{k}_{\mathrm{a}}\right)$ and dissociation $\left(\mathrm{k}_{\mathrm{d}}\right)$ rate constants; only a few techniques to date are able to offer this kind of information (Hahnefeld et al., 2004). The knowledge of separate $\mathrm{k}_{\mathrm{a}}$ and $\mathrm{k}_{\mathrm{d}}$ rate constants is valuable in characterising and selecting the most effective binding partners whether they are for applications of drug discovery or detection. Another major advantage of the SPR over other traditional methods is its label-free detection. Fluorescence and luminescence detections in enzyme-linked immunosorbent assays (ELISA) or radioactive labelling in radioimmunoassays (RIA), in some cases, may not seem favourable, as the labelled tag may occupy important binding sites or cause steric hindrance which could interfere with the biomolecular recognition and interaction events (Gopinath, 2010). Another drawback in labelling of materials for biomolecular interaction is the additional steps required; some can be difficult. 
SPR enables real time monitoring of a binding event between an immobilised ligand and a free flowing analyte in solution. It is the measurement of this interaction that underpins the basis of how a SPR biosensor works. To understand the optical phenomenon of SPR, one must understand the physics of light and its behaviours under certain conditions. When a beam of light at a particular angle (termed as the angle of incidence, $\theta$ ) strikes at the interface of two materials with different refractive indices; one material (glass) having a refractive index higher than the other material (biological buffer solution), the light is completely reflected. This is known as total internal reflection. This total internal reflection continues until the angle of incidence reaches a critical angle, $\theta_{\mathrm{C}}$; at this angle some of the light is refracted across the interface (Figure 1a). If a semi-transparent noble metal (in this example, gold) film is thinly coated on one side of the glass surface (the side that is exposed to buffer solution) then under conditions described above for total internal reflection, surface plasmon resonance can occur. The reason is that at a particular light incident angle, known as the surface plasmon resonance angle, $\theta_{\text {spr, }}$, total internal reflection will not occur (Figure 1b), because some of the light energy is 'transferred' to the metallic gold film. If the intensity of the reflected light is plotted against the angle of incidence, we will observe that at $\theta_{\text {spr }}$ angle the intensity of reflected light is at its minimum (Figure 1c).

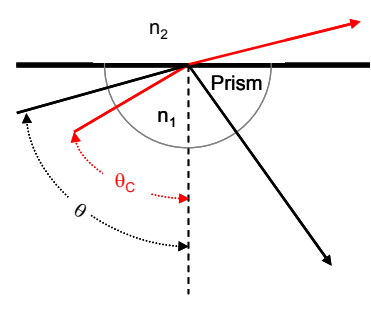

a.

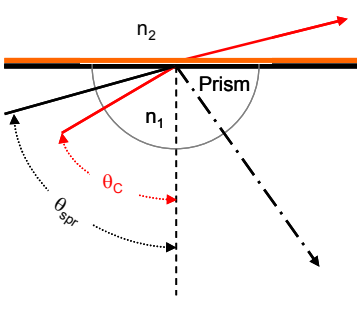

b.

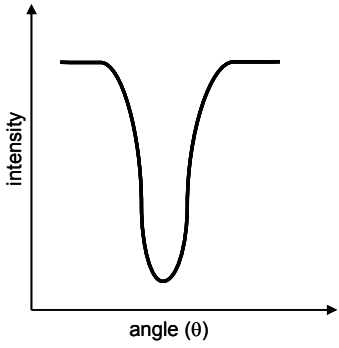

c.

Fig. 1. Schematic diagram of surface plasmon resonance phenomenon. The refractive indices of glass and buffer solution are $\mathrm{n}_{1}$ and $\mathrm{n}_{2}$, respectively; where $\mathrm{n}_{1}>\mathrm{n}_{2}$. Refracted beam at the critical angle, $\theta_{c}$, is shown in red. At angles greater than $\theta_{c}$, light is completely reflected (a). When a thin metallic gold film is coated onto one side of the glass surface, at the surface plasmon resonance angle, $\theta_{\text {spr, }}$ light will not be completely reflected $(\mathbf{b})$. Instead, some of the light energy is transferred to the gold film causing a drop in the intensity of the reflected light at $\theta_{\text {spr }}$ angle (c).

The $\theta_{\text {spr }}$ angle is sensitive to a number of factors such as the incident light wavelength, the nature and thickness of the conducting film and the temperature (Hahnefeld et al., 2004). If all these factors are kept constant, then any shift in the $\theta_{\text {spr }}$ angle will purely be dependent on the refractive index of the buffer solution medium at close proximity to the interface. Changes in the refractive index of this medium during binding events of immobilised ligands and free flowing analytes can then be closely monitored via any shifts in the $\theta_{\text {spr }}$ angle by a photo-detector array equipped as a biosensor instrument. The measurement of the photo-detector array can be visually plotted (Figure 2a). The biosensor instrument processor would convert and quantify these small changes in the $\theta_{\text {spr }}$ angle to absolute resonance units or response units (RU), and plot them against time as sensorgrams (Figure 
$2 \mathrm{~b}$ ), where $1 \mathrm{RU}$ is equivalent to a small change in the $\theta_{\text {spr }}$ angle of about $10^{-4}$ degrees (Hahnefeld et al., 2004).

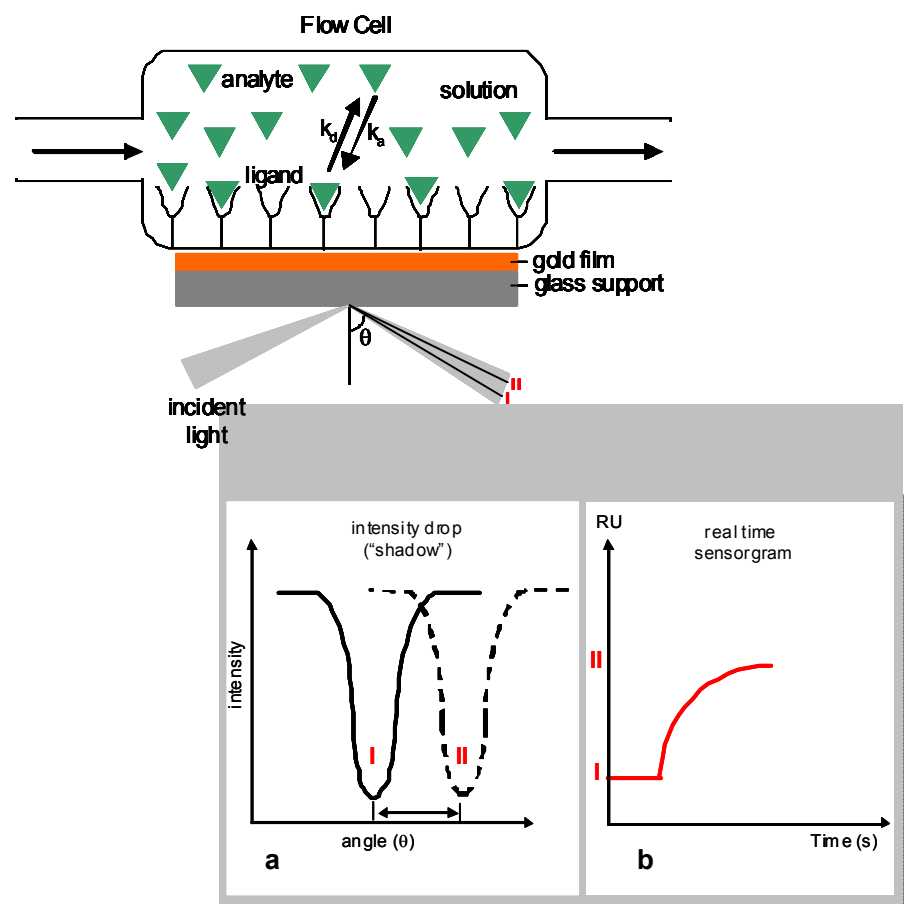

Fig. 2. Schematic illustration of a surface plasmon resonance biosensor. The direction flow of analyte solution is as indicated. As analytes come into contact with immobilised ligands, associations $\left(\mathrm{k}_{\mathrm{a}}\right)$ and dissociations $\left(\mathrm{k}_{\mathrm{d}}\right)$ between the molecules occur. These binding interactions, monitored in real time, will shift the $\theta_{\text {spr }}$ angle from I to II - visually plotted as reflected light intensity against angle of incidence (a). The biosensor will process this change in $\theta_{\text {spr }}$ angle to absolute resonance or response units (RU) and plots the result as a sensorgram $(\mathbf{b})$.

SPR-based biosensors have been used increasingly in the past decade, especially in the postgenomic era where the need to understand the function of biologically important molecules are ever increasing (Gopinath, 2010). The technology is widely used to generate biorecognition information from protein-protein, lipid-protein, nucleic acids and molecular interactions. This information will aid in the screening, discovery and development of therapeutic antibodies and new drugs, the detection and analysis of human pathogens and toxins; and also as a research tool in aptamer selection, epitope mapping, antibody development, ligand fishing and mutant analysis to name a few.

In any application of SPR technology, a single or multiple ligands of interest will need to be firstly immobilised onto the surface of a sensorchip. Ligands can be chemically immobilised onto the sensorchip surface by covalent coupling via primary amines, aldehydes or reactive thiols. Alternatively, high-affinity and specific capture of ligands can also be performed via 
streptavidin interactions, fusion tags, interactions between antibodies or ligand-specific interactions. This step aims to change the surface chemistry in preparation for subsequent interaction with injected free-flowing analytes. When analyte solution is flown over ligands; immobilised or captured, the interactions between the molecules are monitored in real time. A sensorgram is shown in Figure 3, three phases are involved in a typical biomolecular interaction study on a SPR biosensor.

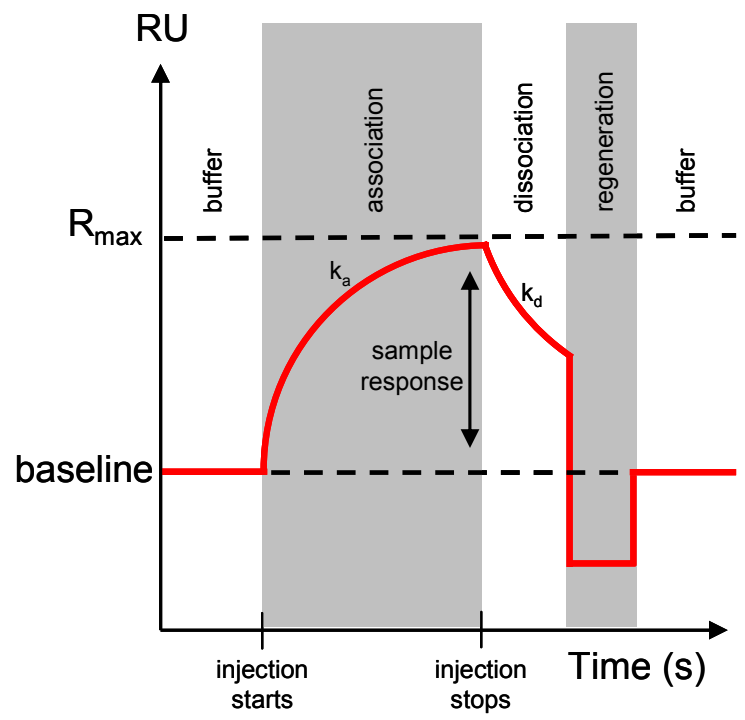

Fig. 3. A typical SPR sensorgram showing the three phases involve in a biomolecular interaction study. The three phases are: association, dissociation and regeneration.

These phases are association, dissociation and regeneration. Understanding the events and significance of each phase is important, as they are required in obtaining kinetic data about the interaction; such as the association $\left(\mathrm{k}_{\mathrm{a}}\right)$ and dissociation $\left(\mathrm{k}_{\mathrm{d}}\right)$ rate constants as well as the apparent equilibrium binding constant $\left(\mathrm{k}_{\mathrm{D}}\right.$ or $\left.\mathrm{k}_{\mathrm{A}}\right)$. In an SPR experiment, biomolecular interaction analysis can only be performed after a stable sensorgram baseline is achieved with continuous running buffer flown over immobilised or captured ligands. In the association phase, an analyte solution is injected and flown over the ligand surface where biomolecular interaction between the two, if exists, will occur. This interaction is amplified by an increase in the response unit (RU) on the sensorgram as shown in Figure 3. As more interactions take place between analytes and ligands this will also translate to a corresponding increase in the RU on the sensorgram, which will continue until it reaches its highest binding RU value, usually at the end of an analyte injection. This highest RU sometime can also be the maximum binding capacity $\left(R_{\max }\right)$. This occurs when analytes are fast and strong binders to the ligand causing these analytes to fully occupy all available ligand binding sites.

Dissociation phase starts when the injection of the analyte solution stops and the system switches to continuous flow of running buffer. Under this condition, dissociation between analytes and ligands is greatly favoured over association. As analytes dissociate from 
ligands, this event is reflected by a decrease in RU on the sensorgram as shown in Figure 3. In many cases, analyte dissociation is never complete or it takes far too long to observe complete dissociation. Hence, an additional step to aid this process may be incorporated into the regeneration phase, which involves the injection of an appropriate regeneration solution to remove excess bound analytes that have not yet dissociated. The ultimate goal is to elute non-covalently bound analytes but at the same time not adversely disrupt the biological activity of the ligand in the process. At the end of the regeneration phase, a baseline RU is reached and ready for subsequent use, hence saving time and resources. However, it is often that ideal regeneration conditions are hard and time consuming to establish, in which cases it may be more effective to settle for non-ideal regeneration.

\section{Reagents and instruments used for assay development}

Several anti-BoNT rabbit polyclonal antibodies (PAb), purchased from Metabiologics Inc (Wisconsin, USA), were used as the ligands in this study; they were Anti-BoNT/A PAb (Lot. No. A011708-01) and Anti-BoNT/B PAb (Lot No. B082203-01), each supplied in $100 \mathrm{mM}$ Tris/glycine buffer ( $\mathrm{pH}$ 7.9). Purified botulinum toxins (BoNTs) and formalin-inactivated toxoids (BoTds) (also from Metabiologics Inc) were used as the analytes, including BoNT/A (Lot No. A031009-01), BoNT/B (Lot No. B031009-01), BoTd/A (Lot No. A090805-01) and BoTd/B (Lot No. B090705-01). The toxins were supplied in $0.22 \mu \mathrm{m}$ filtered phosphatebuffered saline (PBS) ( $\mathrm{pH}$ 7.0). All toxins and antibodies were kept refrigerated before use.

For enzyme linked immunosorbent assay (ELISA), the following buffers were prepared: coating buffer [0.05 M carbonate-bicarbonate buffer, $\mathrm{pH}$ 9.6]; wash buffer [PBS containing $0.05 \%$ Tween 20 (PBST)]; blocking solution and reagent diluent [3\% skim milk in PBST (M-PBST)]. Substrate para-nitrophenyl phosphate (pNPP) tablets were purchased from Sigma-Aldrich (Sydney, Australia). A working volume of $100 \mu \mathrm{l}$ per well was used in the ELISA, except for the blocking step, which was $350 \mu \mathrm{l}$ per well. BoNTs or BoTds, diluted in coating buffer, were coated onto the wells of a Nunc-Immuno MaxiSorp microtitre plate (Invitro Technologies, Melbourne, Australia, cat. no. 43954) and incubated overnight at $4^{\circ} \mathrm{C}$ ( 16 hours). Antibodies were subsequently added, all of which were diluted in M-PBST. Incubations of primary (anti-BoNT PAb at $0.5 \mu \mathrm{g} / \mathrm{ml}$ ) and secondary (anti-rabbit IgG-AP diluted 1:10,000) antibodies were carried out for 1 hour at room temperature with shaking. After each incubation step, the plate was washed with PBST ( 3 X $350 \mu$ per well). The final washing step (after anti-rabbit IgG-AP incubation) involved PBST washes (3 times) and a distilled water wash. This was followed by the addition of substrate solution. Substrate incubation was 1 hour at room temperature with shaking before the plate was read at wavelength $405 \mathrm{~nm}$.

The instruments used included the SPR BIAcore ${ }^{\circledR}$ X (GE Healthcare, NSW, Australia), Labsystems Wellwash Mk2 plate washer (Pathtech, Melbourne, Australia), Ratek plate shaker (Ratek Instruments, Melbourne, Australia) and Labsystems Multiskan Ascent Photometric plate reader (Pathtech, Melbourne, Australia). The BIAcore ${ }^{\circledR}$ X system comprises the BIAcore ${ }^{\circledR} X$ instrument, BIAcore ${ }^{\circledR}$ X Control Software (Version 2.2) and BIAevaluation software (Version 4.1). The following reagents were also purchased from GE Healthcare: CM5 sensor chip (research grade), HBS-EP running buffer (0.01 M HEPES pH 7.4, $0.15 \mathrm{M} \mathrm{NaCl}, 3 \mathrm{mM}$ EDTA and $0.005 \% \mathrm{v} / \mathrm{v}$ Surfactant P20), and amine coupling kit 
containing $115 \mathrm{mg} / \mathrm{ml} \quad \mathrm{N}$-hydroxysuccinimide (NHS), $750 \mathrm{mg} / \mathrm{ml} \quad$ 1-ethyl-3-(3dimethylamino-propyl) carbodiimide hydrochloride (EDC) and $1.0 \mathrm{M}$ ethanolamine- $\mathrm{HCl}$, $\mathrm{pH}$ 8.5. All other chemicals used for buffer preparations were purchased from SigmaAldrich (Sydney, Australia).

\section{Surface functionalisation}

In the SPR assay system, specific antibodies need to be immobilised onto the surface of a SPR sensor chip in order to create favourable surface chemistry that is necessary for interaction between BoTd and its antibody. In this study, commercial PAbs produced in rabbits immunised with BoNT/A and BoNT/B were immobilised onto a CM5 sensor chip. Firstly, carboxymethylated dextrans covalently attached to the gold surface of the sensor chip were activated by chemical treatment to form N-hydroxysuccinimide esters. This was performed with an injection ( $35 \mu \mathrm{l})$ of a mixture of equal volumes of EDC and NHS at a flow rate of $5 \mu \mathrm{l} / \mathrm{min}$. This activation permitted the reactive succinimide ester surface to covalently bind injected anti-BoNT PAbs $(50 \mu \mathrm{l}$ at concentration of $50 \mu \mathrm{g} / \mathrm{ml}$ diluted in immobilisation buffer, $10 \mathrm{mM}$ sodium acetate, $\mathrm{pH} 4.5)$ via its free amino groups. A final 35 $\mu \mathrm{l}$ injection of $1 \mathrm{M}$ ethanolamine, $\mathrm{pH} 8.5$ was passed over the sensor chip surface to deactivate and block residual active esters from any further reaction.

The assay procedure involved injecting a continuous flow of sample solution (50 $\mu \mathrm{l}$ at a flow rate of $5 \mu \mathrm{l} / \mathrm{min}$ ), over a sensor chip surface immobilised with a specific antibody. This sample solution first passed over a blank control channel (Flow Cell 1) before flowing over an anti-BoNT PAb immobilised surface channel (Flow Cell 2). Interactions between the injected BoTd and the immobilised anti-BoNT PAb were monitored by plotting the output signal as a sensorgram. During the injection period, BoTd detection could be observed in real-time from rising sensorgram signal. At the completion of sample injection, the final observed sensorgram signal in resonance units (RU) corresponded to the maximum binding that had occurred for a particular sample. At the chosen flow rate of $5 \mu \mathrm{l} / \mathrm{min}$, an assay took approximately 10 minutes to complete. At the completion of an assay, the sensor chip was regenerated for further assays. This was performed by injecting short pulses of a regeneration buffer over the sensor chip surface to remove non-covalently bound BoTd. The regeneration buffer chosen for this assay was $10 \mathrm{mM}$ glycine- $\mathrm{HCl}, \mathrm{pH} 1.75$ with $0.01 \%(\mathrm{v} / \mathrm{v})$ Tween 20. The generated sensorgram data was analysed by the BIAevaluation software (Version 4.1).

\section{Assay development and optimisation}

Our preliminary ELISA results revealed that the two anti-toxin PAbs could recognise both the native toxins and the formalin-inactivated toxoids for serotypes A and B (data not shown). For safety reasons, only the toxoids were used for the BIAcore ${ }^{\circledR} \mathrm{X}$ system. Each CM5 sensor chip contained two flow cells, but only one of which (i.e. Flow Cell 2) had antiBoNT PAbs immobilised. The difference in Resonance Units $(\Delta R U)$ obtained between preligand (anti-BoNT PAb) injection and post sensor chip deactivation indicates the amount of anti-BoNT PAb immobilised. As a general rule, $1 \mathrm{ng}$ of immobilised antibodies per $\mathrm{mm}^{2}$ equates to approximately 1,000 RU. For our anti-BoNT PAbs used, $\Delta R U$ values in the range 
of 2,500 to 3,500 RU were obtained consistently using the immobilisation conditions described above. This corresponds to approximately 2.5 to $3.5 \mathrm{ng}$ of anti-BoNT PAbs immobilised per $\mathrm{mm}^{2}$ for either serotype. On the same sensor chip, Flow Cell 1 was used as a negative control, for which the same immobilisation procedure was carried out without ligand injection. This means the surface on Flow Cell 1 was activated, exposed to ligand-free immobilisation solution and deactivated. Flow Cell 1 was required for non-specific and background signal corrections as sample solution was injected onto the sensor chip flowing through Flow Cell 1 first and then onto Flow Cell 2.

A flow rate of $5 \mu \mathrm{l} / \mathrm{min}$ was selected in order to enhance binding conditions of the assay. This slow flow rate allowed sufficient time for the injected BoTds and the immobilised antiBoNT PAbs to interact. Samples containing BoTd/A or BoTd/B at various concentrations were each assayed in triplicate to determine the assay's standard deviation and co-efficient of variation. After each sample injection, sensorgram signals (RU) at intervals of $50 \mu \mathrm{l}$ and $100 \mu \mathrm{l}$ were recorded and plotted (Figure 4). Similar detection signals were obtained with each serotype SPR assay even though each sensor chip had different anti-BoNT PAbs immobilised on it. As predicted, at the same BoTd concentration, SPR detection signals observed at $100 \mu \mathrm{l}$ of the loaded sample were greater than that of $50 \mu \mathrm{l}$. The increase in detection signals obtained from injections of $100 \mu \mathrm{l}$ of sample compared to $50 \mu \mathrm{l}$ was less than two-fold. This increase was not deemed significant to justify doubling of the assay time (at flow rate of $5 \mu \mathrm{l} / \mathrm{min}$, an assay of $100 \mu \mathrm{l}$ injection would take 20 minutes to complete). On the other hand, a $50 \mu \mathrm{l}$ sample injection would only require 10 minutes to complete an assay and still produced considerable and observable RU signals. Therefore, it was concluded that a sample injection volume of $50 \mu \mathrm{l}$, corresponding to an assay time of just 10 minutes, would be appropriate, sufficient and beneficial for rapid detection methods such as this SPR assay.

The co-efficient of variations amongst the triplicate results varied from 5\% to $13 \%$ (data not shown). Compared to other similar SPR assays, these values were considered to be relatively high although they were still acceptable. Ineffective regeneration conditions could be a reason for this higher than expected variation. Ideally, conditions for sensor chip regeneration should be such that they are harsh enough to dissociate all bound analytes while at the same time having minimal to neutral effects on immobilised antibodies of the assay. Despite repeated efforts, the final procedure developed for the assay regeneration in this study does not appear to be optimal and effective (data not shown). This could result in (i) ineffective dissociation of the bound BoTds and/or (ii) partial inactivation of the antiBoNT PAbs immobilised on the sensor surface. Either or both of these could reduce the number of accessible binding sites after each regeneration cycle, hence leading to higher than expected variations in replicate results.

Based on experimental results, the assay's limit of detection (LOD) was estimated to be less than $50 \mathrm{ng}$ of loaded BoTd amounts, for either serotype (Figure 4). For BoTd amounts below the LOD, RU signals were found to be in the range of 1 to 4 RU. This RU signal range was similar to or below that of the assay LOD signal. This indicates that the assay signal had reached its lower limit, hence stabilising around this RU range even at sub LOD levels. Compared to a blank control injection, negative RU values were often observed. 
A.

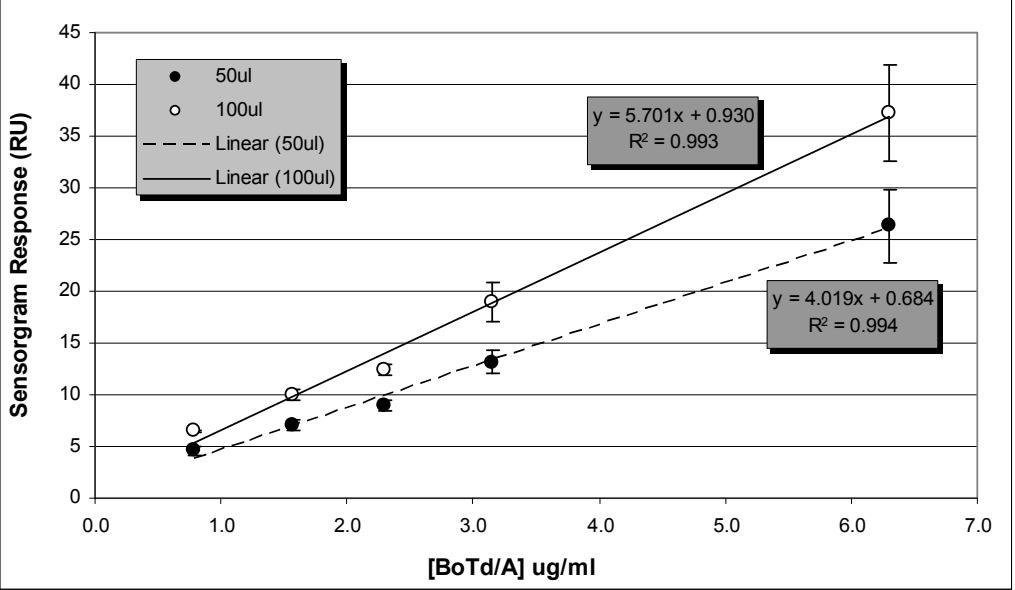

B.

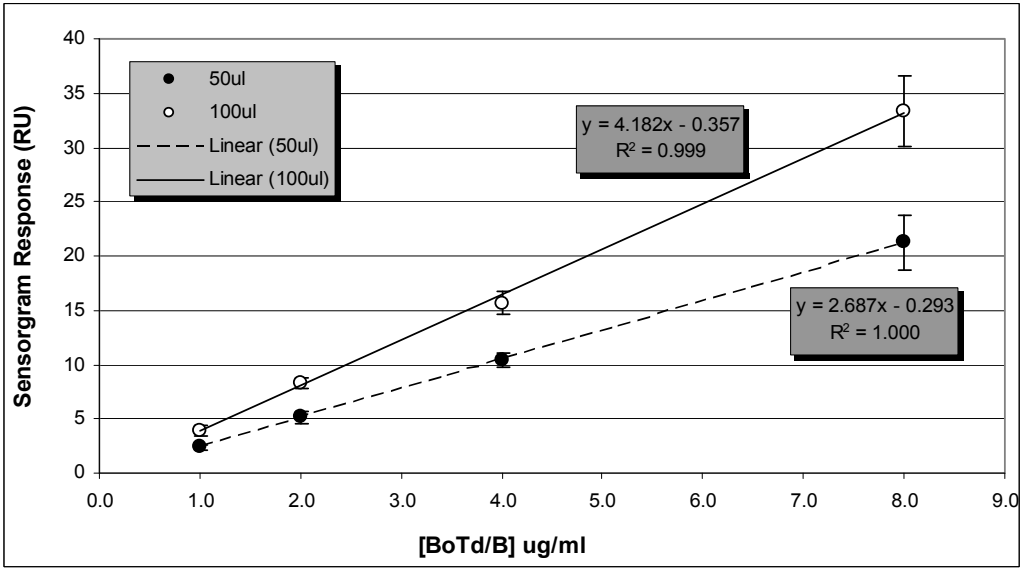

Fig. 4. SPR assay derived standard curves for BoTds; serotypes A (A) and B (B). Error bars are mean \pm standard deviation where $\mathrm{n}=3$.

\section{Detection of environmental samples and cross-reactivity}

Environmental aerosol samples were collected at different Melbourne sites using a horizontal wet wall cyclone (HWWC). The cyclone is a large volume air sampler that collects ambient aerosol particles at the rate of $\sim 800$ litres of air per minute and concentrates these particles into a $10 \mathrm{ml}$ solution. This solution, termed cyclone buffer, was made up of water and Tween $80(0.01 \% \mathrm{v} / \mathrm{v})$. These liquid samples were centrifuged and the supernatants were collected as environmental samples (ES). Five ES were assayed, each sample was spiked with BoTds (50 ng loading amounts). Table 1 shows that the assay could be used to detect BoTds, albeit with reduced sensitivity, in environmental aerosol samples. The reduced signals obtained from these spiked ES, compared to spiked cyclone buffer, may suggest inhibitory effects on assay sensitivity from ES testing. 


\begin{tabular}{l|l|l}
\hline \multirow{2}{*}{ Sample } & \multicolumn{2}{|c}{ Recovery (\%) } \\
\cline { 2 - 3 } & \multicolumn{1}{|c}{ BoTd/A } & \multicolumn{1}{|c}{ BoTd/B } \\
\hline cyclone buffer & $100.0(13.3)$ & $100.0(7.7)$ \\
ES00338 & $59.3(15.2)$ & $72.6(6.5)$ \\
ES00352 & $45.3(11.5)$ & $26.3(5.0)$ \\
ES00285 & $58.7(8.9)$ & $51.6(8.4)$ \\
ES00316 & $59.3(7.2)$ & $51.6(5.1)$ \\
ES00304 & $87.3(9.8)$ & $90.7(5.2)$ \\
\hline
\end{tabular}

Table 1.BoTd-spiked environmental samples. An amount of $50 \mathrm{ng}$ of toxoid was loaded onto the sensor chip for each sample. Percentage recovery was calculated based on spiked cyclone buffer signal. Each sample was assayed in duplicate. Values next to recovery percentage, in brackets, are the calculated percentage $\mathrm{CV}$.

A simple examination of the assay for cross-reactivity was performed by observing the detection signal generated by another closely related serotype toxoid, in this case, an injection of BoTd/A onto anti-BoNT/B PAb immobilised sensor chip, and vice-versa. Neither SPR assay showed any cross-reactivity with its related serotype BoTd. The RU signals generated are shown in Table 2. Visually, there was little or no cross-reactivity in either SPR assay, as illustrated by the respective sensorgrams, shown in Figure 5.

\begin{tabular}{l|l|l}
\hline \multirow{2}{*}{ Immobilised Sensor Chip } & \multicolumn{2}{|l}{ RU signal } \\
\cline { 2 - 3 } & BoTd/A & BoTd/B \\
\hline Anti-BoNT/A PAb & 22.0 & 2.3 \\
Anti-BoNT/B PAb & 3.6 & 44.0 \\
\hline
\end{tabular}

Table 2. SPR assay cross-reactivity testing using toxoids BoTd/A and BoTd/B, each loaded at $250 \mathrm{ng}$ onto the sensor chip.

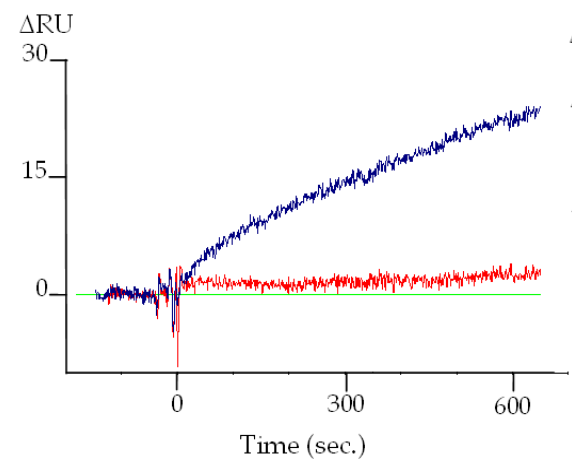

A.

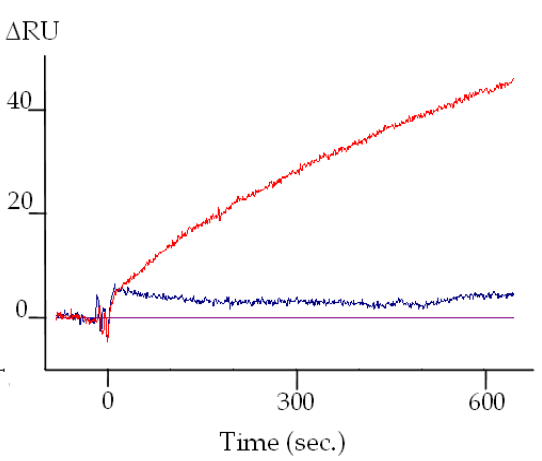

B.

Fig. 5. SPR assay sensorgrams showing minimal cross-reactivity for (A) toxoid BoTd/A and (B) BoTd/B. 


\section{Estimation of assay sensitivity for active toxins}

To estimate the sensitivity of the SPR assay to detect active toxins, ELISA was used to evaluate the two anti-BoNT PAbs used in the SPR assay for their relative binding affinities to the toxins and their toxoids. Toxins BoNT/A and BoNT/B and their corresponding toxoids were coated separately onto the wells of microtitre plates. These analytes were then assayed using their respective anti-BoNT PAbs. ELISA detection signals, measured as optical density (OD) at $405 \mathrm{~nm}$, at various BoNT and BoTd concentrations were plotted for comparisons. Typical ELISA signal curves of BoNTs and BoTds are shown in Figure 6. The anti-BoNT PAbs were found to have a higher binding affinity for the toxins than for the toxoids for both serotypes. Based on the data obtained, both BoNTs were calculated to be at least 40-fold more reactive than their counter-part BoTds with the anti-BoNT PAbs. This was to be expected because the anti-BoNT PAbs were raised specifically against the BoNTs, hence they recognised the BoNTs more favourably and effectively than the BoTds. From the correlation curves, the detection limit of our SPR assay of $50 \mathrm{ng}$ for toxoids can be estimated to an approximate amount of $1.3 \mathrm{ng}$ for BoNTs.

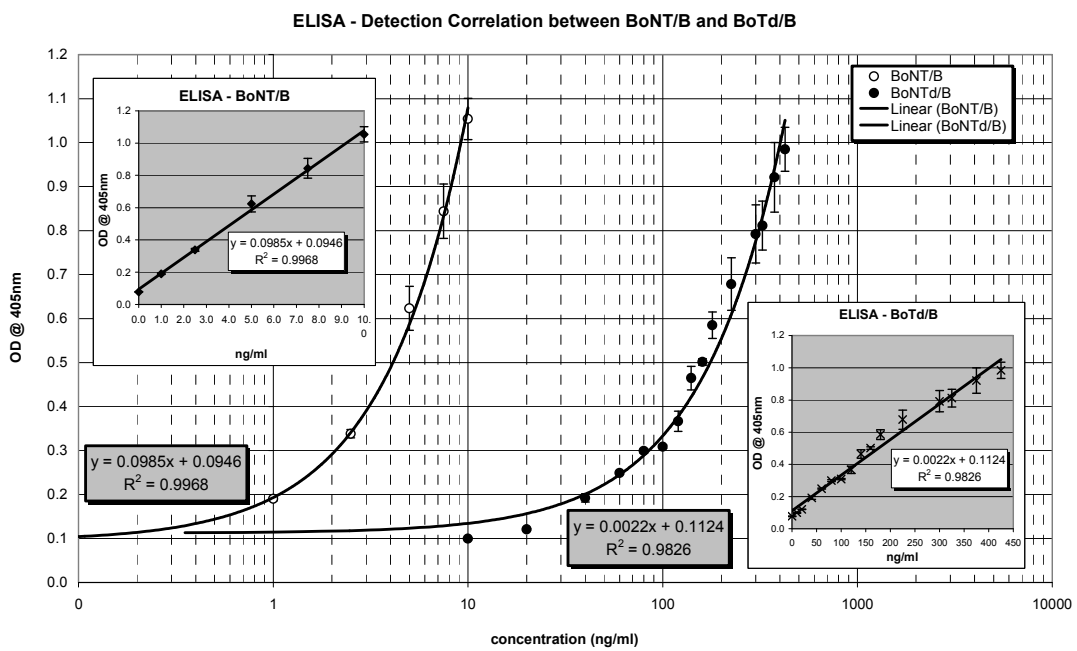

Fig. 6. Correlations in detection sensitivity between toxin BoNT/B and toxoid BoTd/B. ELISA signal, OD at $405 \mathrm{~nm}$, plotted against coated toxin or toxoid concentrations.

The stability of the toxins stored at $4{ }^{\circ} \mathrm{C}$ was also investigated. It was found that ELISA signals obtained for $5 \mathrm{ng} / \mathrm{ml}$ of coated toxins were gradually reduced over a period of a year, despite refrigeration storage of the toxins. The signals reduced significantly, more than 50 percent, within 6 months of toxin production and it appeared that the rate of degradation was greater for BoNT/A than for BoNT/B (data not shown). This is in agreement with other publications that BoNT itself is less stable than BoNT complex (Brandau et al., 2007). The complex consists of BoNT and its non-toxic associated proteins, which is believed to protect the neurotoxin against damage from exposure to extreme conditions. The increased thermal stability of the BoNT complex may have risen from the internal structure of the complex generated by interactions between BoNT itself and the associated non-toxic proteins (Brandau et al., 2007). 


\section{Discussion and concluding remarks}

Here, we report the development of a real-time optical SPR assay using formalin inactivated toxins, BoTds. The data were then correlated back to their active toxin BoNT values by assessing the same anti-BoNT PAbs for their binding affinities to both BoNTs and BoTds in an ELISA setting. This indirect evaluation of an SPR assay for BoNT detection is less than ideal, but it is a requirement for the SPR instrument due to safety concerns. Unlike other models, the BIAcore ${ }^{\circledR} X$ does not have an enclosed sample injection compartment or an automatic injector. Therefore, samples need to be manually injected into the BIAcore ${ }^{\circledR} \mathrm{X}$ in an open area environment where toxin aerolisation and inhalation would pose a possible risk.

The SPR assay developed has several advantages over other assays in that it is rapid, provides real-time detection following sample injection, and requires no reagents to be labelled. The assay has an estimated LOD of $1.3 \mathrm{ng}$ of loaded BoNTs for both serotypes, a value obtained based on BoTd experimental data. A similar SPR assay has been previously reported by Ladd et al (Ladd et al., 2008), which, however, requires at least 60 minutes to complete an assay plus a further 2 hours for preparation prior to the actual assay. In comparison, our SPR assay takes only 10 minutes to complete, and in fact, the entire procedure from antibody immobilisation to completing an SPR assay takes less than 40 minutes. Furthermore, our assay does not require the preparation for antibody biotinylation, purification and immobilisation and the addition of another antibody to achieve the LOD.

Examples of other technologies being used for BoNT detection include ELISA (Ferreira et al., 2003; Poli et al., 2002; Sharma et al., 2006; Wictome et al., 1999; Wictome et al., 1999), mass spectrometry (Barr et al., 2005; Boyer et al., 2005; Kalb et al., 2005; Kalb et al., 2006), enzyme-amplified protein micro-array immunoassay (Varnum et al., 2006), fluorometric biosensor (Dong et al., 2004), and a modified immunoassay (Bagramyan et al., 2008), which measures the intrinsic metalloprotease activity with a fluorogenic substrate. Although some of these assays are more sensitive than the SPR assay, they do not offer real-time detection, often require antibodies to be labelled, which can create problems in antibody-antigen recognition, and most importantly these assays are laborious. Assays based on polymerase chain reaction (PCR) have also been reported; however, these assays can only detect the presence of residual bacterial DNA if present in BoNT samples (Fach et al., 2009; Lindstrom \& Korkeala, 2006). Therefore, they are not applicable to toxin samples of high purity (i.e. toxin samples where they do not contain any residual bacterial DNA).

The option of incorporating another antibody into our SPR assay was not investigated. This additional step would theoretically provide a larger SPR response, effectively amplifying the output signal and increasing the assay sensitivity. The significance of enhanced sensitivity should be investigated to determine whether the benefit warrants a longer assay time.

Successful regeneration of sensor chip surface is critical for any SPR assay as it allows multiple assays to be performed. An ideal regeneration condition should be such that it dissociates and removes all bound molecules but does not damage the biological activity of immobilised antibodies on the chip. The present assay has a coefficient of variation ranging from $5 \%$ to $13 \%$, which was a rather high value compared to other SPR assays. This could 
be caused by an ineffective regeneration of the chip surface. It was also possible that the immobilised antibody surface might have been damaged or that the bound BoTds might have not been effectively removed. Either, or both, of these would contribute to a reduction in the number of accessible binding sites after each regeneration cycle.

The cross reactivity of the assay was evaluated against two closely related serotypes BoTd/A and BoTd/B. Although the experiment was simple and limited, our results showed that the assay did not cross-react with its closely related BoTd serotype, suggesting minimal cross-reactivity issues with other non-related toxins. Both assays also detected BoTd-spiked environmental samples, although all signals were reduced when compared to spiked cyclone buffers. The signal reduction suggests possible inhibitory effects of the sample on the immobilised anti-BoNT PAbs, and consequently on their assay sensitivity. Further studies with a larger number of environmental samples should be performed to provide more information concerning the detection of native toxins in different sample matrices and cross-reactivity with other toxins or contaminants. In addition, more stable anti-BoNT antibodies should be sought because like other immunoassays, the SPR assay also relies heavily on the use of high quality antibodies that are not only highly specific for their targets but are also able to withstand the harsh regeneration process.

\section{Acknowledgement}

We thank Dr Ray Dawson for critical reading of the manuscript.

\section{References}

Arnon, S. S., Schechter, R., Inglesby, T. V., Henderson, D. A., Bartlett, J. G., Ascher, M. S., Eitzen, E., Fine, A. D., Hauer, J., Layton, M., Lillibridge, S., Osterholm, M. T., O'Toole, T., Parker, G., Perl, T. M., Russell, P. K., Swerdlow, D. L. \& Tonat, K. (2001). Botulinum toxin as a biological weapon: medical and public health management. Jama, 285(8), 1059-70.

Aureli, P., Fenicia, L., Pasolini, B., Gianfranceschi, M., McCroskey, L. M. \& Hatheway, C. L. (1986). Two cases of type E infant botulism caused by neurotoxigenic Clostridium butyricum in Italy. J Infect Dis, 154(2), 207-11.

Bagramyan, K., Barash, J. R., Arnon, S. S. \& Kalkum, M. (2008). Attomolar detection of botulinum toxin type A in complex biological matrices. PLoS One, 3(4), e2041.

Barr, J. R., Moura, H., Boyer, A. E., Woolfitt, A. R., Kalb, S. R., Pavlopoulos, A., McWilliams, L. G., Schmidt, J. G., Martinez, R. A. \& Ashley, D. L. (2005). Botulinum neurotoxin detection and differentiation by mass spectrometry. Emerg Infect Dis, 11(10), 157883.

Bossi, P., Tegnell, A., Baka, A., van Loock, F., Hendriks, J., Werner, A., Maidhof, H. \& Gouvras, G. (2004). Bichat guidelines for the clinical management of botulism and bioterrorism-related botulism. Euro Surveill, 9(12), E13-4.

Boyer, A. E., Moura, H., Woolfitt, A. R., Kalb, S. R., McWilliams, L. G., Pavlopoulos, A., Schmidt, J. G., Ashley, D. L. \& Barr, J. R. (2005). From the mouse to the mass 
spectrometer: detection and differentiation of the endoproteinase activities of botulinum neurotoxins A-G by mass spectrometry. Anal Chem, 77(13), 3916-24.

Brandau, D. T., Joshi, S. B., Smalter, A. M., Kim, S., Steadman, B. \& Middaugh, C. R. (2007). Stability of the Clostridium botulinum type A neurotoxin complex: an empirical phase diagram based approach. Mol Pharm, 4(4), 571-82.

Cai, S., Sarkar, H. K. \& Singh, B. R. (1999). Enhancement of the endopeptidase activity of botulinum neurotoxin by its associated proteins and dithiothreitol. Biochemistry, 38(21), 6903-10.

Cai, S., Singh, B. R. \& Sharma, S. (2007). Botulism diagnostics: from clinical symptoms to in vitro assays. Crit Rev Microbiol, 33(2), 109-25.

Dembek, Z. F., Smith, L. A. \& Rusnak, J. M. (2007). Botulism: cause, effects, diagnosis, clinical and laboratory identification, and treatment modalities. Disaster Med Public Health Prep, 1(2), 122-34.

Dong, M., Tepp, W. H., Johnson, E. A. \& Chapman, E. R. (2004). Using fluorescent sensors to detect botulinum neurotoxin activity in vitro and in living cells. Proc Natl Acad Sci U S A, 101(41), 14701-6.

Fach, P., Micheau, P., Mazuet, C., Perelle, S. \& Popoff, M. (2009). Development of real-time PCR tests for detecting botulinum neurotoxins A, B, E, F producing Clostridium botulinum, Clostridium baratii and Clostridium butyricum. J Appl Microbiol, 107(2), 465-73.

Ferreira, J. L., Maslanka, S., Johnson, E. \& Goodnough, M. (2003). Detection of botulinal neurotoxins A, B, E, and F by amplified enzyme-linked immunosorbent assay: collaborative study. J AOAC Int, 86(2), 314-31.

Gill, D. M. (1982). Bacterial toxins: a table of lethal amounts. Microbiol Rev, 46(1), 86-94.

Gopinath, S. C. B. (2010). Biosensing applications of surface plasmon resonance-based Biacore technology. Sensors and Actuators B, 150, 722-723.

Hahnefeld, C., Drewianka, S. \& Herberg, F. W. (2004). Determination of kinetic data using surface plasmon resonance biosensors. Methods Mol Med, 94, 299-320.

Hall, J. D., McCroskey, L. M., Pincomb, B. J. \& Hatheway, C. L. (1985). Isolation of an organism resembling Clostridium barati which produces type $\mathrm{F}$ botulinal toxin from an infant with botulism. J Clin Microbiol, 21(4), 654-5.

Hicks, R. P., Hartell, M. G., Nichols, D. A., Bhattacharjee, A. K., van Hamont, J. E. \& Skillman, D. R. (2005). The medicinal chemistry of botulinum, ricin and anthrax toxins. Curr Med Chem, 12(6), 667-90.

Inoue, K., Fujinaga, Y., Watanabe, T., Ohyama, T., Takeshi, K., Moriishi, K., Nakajima, H., Inoue, K. \& Oguma, K. (1996). Molecular composition of Clostridium botulinum type A progenitor toxins. Infect Immun, 64(5), 1589-94.

Kalb, S. R., Goodnough, M. C., Malizio, C. J., Pirkle, J. L. \& Barr, J. R. (2005). Detection of botulinum neurotoxin $\mathrm{A}$ in a spiked milk sample with subtype identification through toxin proteomics. Anal Chem, 77(19), 6140-6.

Kalb, S. R., Moura, H., Boyer, A. E., McWilliams, L. G., Pirkle, J. L. \& Barr, J. R. (2006). The use of Endopep-MS for the detection of botulinum toxins A, B, E, and F in serum and stool samples. Anal Biochem, 351(1), 84-92. 
Kautter, D. A. \& Solomon, H. M. (1977). Collaborative study of a method for the detection of Clostridium botulinum and its toxins in foods. J Assoc Off Anal Chem, 60(3), 541-5.

Kulagina, N. V., Anderson, G. P., S., L. F., M., S. K. \& Taitt, C. R. (2007). Antimicrobial Peptides: New Recognition Molecules for Detecting Botulinum Toxins. Sensors, 7, 2808-2824.

Ladd, J., Taylor, A. D., Homola, J. \& Jiang, S. (2008). Detection of botulinum neurotoxins in buffer and honey using surface plasmon resonance (SPR) sensor. Sensors and Actuators B, 130, 129-134.

Lindstrom, M. \& Korkeala, H. (2006). Laboratory diagnostics of botulism. Clin Microbiol Rev, 19(2), 298-314.

Montecucco, C. \& Molgo, J. (2005). Botulinal neurotoxins: revival of an old killer. Curr Opin Pharmacol, 5(3), 274-9.

Poli, M. A., Rivera, V. R. \& Neal, D. (2002). Development of sensitive colorimetric capture ELISAs for Clostridium botulinum neurotoxin serotypes E and F. Toxicon, 40(6), 797-802.

Poras, H., Ouimet, T., Orng, S. V., Fournie-Zaluski, M. C., Popoff, M. R. \& Roques, B. P. (2009). Detection and quantification of botulinum neurotoxin type a by a novel rapid in vitro fluorimetric assay. Appl Environ Microbiol, 75(13), 4382-90.

Schantz, E. J. \& Johnson, E. A. (1992). Properties and use of botulinum toxin and other microbial neurotoxins in medicine. Microbiol Rev, 56(1), 80-99.

Scott, A. B. \& Suzuki, D. (1988). Systemic toxicity of botulinum toxin by intramuscular injection in the monkey. Mov Disord, 3(4), 333-5.

Sharma, S. K., Ferreira, J. L., Eblen, B. S. \& Whiting, R. C. (2006). Detection of type A, B, E, and $\mathrm{F}$ Clostridium botulinum neurotoxins in foods by using an amplified enzymelinked immunosorbent assay with digoxigenin-labeled antibodies. Appl Environ Microbiol, 72(2), 1231-8.

Simpson, L. L. (2004). Identification of the major steps in botulinum toxin action. Annu Rev Pharmacol Toxicol, 44, 167-93.

Singh, B. R. (2006). Botulinum neurotoxin structure, engineering, and novel cellular trafficking and targeting. Neurotox Res, 9(2-3), 73-92.

Singh, B. R. (2000). Intimate details of the most poisonous poison. Nat Struct Biol, 7(8), 6179.

Sugiyama, H. (1980). Clostridium botulinum neurotoxin. Microbiol Rev, 44(3), 419-48.

Varnum, S. M., Warner, M. G., Dockendorff, B., Anheier, N. C., Jr., Lou, J., Marks, J. D., Smith, L. A., Feldhaus, M. J., Grate, J. W. \& Bruckner-Lea, C. J. (2006). Enzymeamplified protein microarray and a fluidic renewable surface fluorescence immunoassay for botulinum neurotoxin detection using high-affinity recombinant antibodies. Anal Chim Acta, 570(2), 137-43.

Wictome, M., Newton, K., Jameson, K., Hallis, B., Dunnigan, P., Mackay, E., Clarke, S., Taylor, R., Gaze, J., Foster, K. \& Shone, C. (1999). Development of an in vitro bioassay for Clostridium botulinum type B neurotoxin in foods that is more sensitive than the mouse bioassay. Appl Environ Microbiol, 65(9), 3787-92. 
Wictome, M., Newton, K. A., Jameson, K., Dunnigan, P., Clarke, S., Gaze, J., Tauk, A., Foster, K. A. \& Shone, C. C. (1999). Development of in vitro assays for the detection of botulinum toxins in foods. FEMS Immunol Med Microbiol, 24(3), 319-23. 


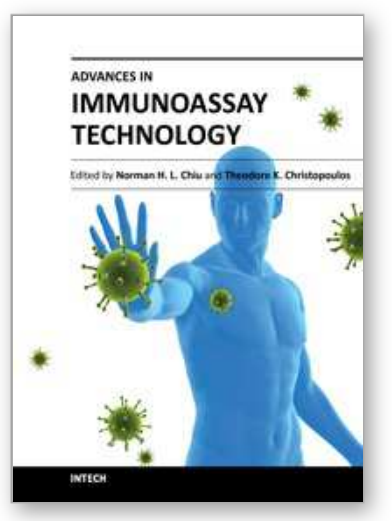

\author{
Advances in Immunoassay Technology \\ Edited by Dr. Norman H. L. Chiu
}

ISBN 978-953-51-0440-7

Hard cover, 180 pages

Publisher InTech

Published online 23, March, 2012

Published in print edition March, 2012

From the basic in vitro study of a specific biomolecule to the diagnosis or prognosis of a specific disease, one of the most widely used technology is immunoassays. By using a specific antibody to recognize the biomolecule of interest, relatively high specificity can be achieved by immunoassays, such that complex biofluids (e.g. serum, urine, etc.) can be analyzed directly. In addition to the binding specificity, the other key features of immunoassays include relatively high sensitivity for the detection of antibody-antigen complexes, and a wide dynamic range for quantitation. Over the past decade, the development and applications of immunoassays have continued to grow exponentially. This book focuses on some of the latest technologies for the development of new immunoassays.

\title{
How to reference
}

In order to correctly reference this scholarly work, feel free to copy and paste the following:

Hung Tran and Chun-Qiang Liu (2012). Label-Free Detection of Botulinum Neurotoxins Using a Surface Plasmon Resonance Biosensor, Advances in Immunoassay Technology, Dr. Norman H. L. Chiu (Ed.), ISBN: 978-953-51-0440-7, InTech, Available from: http://www.intechopen.com/books/advances-in-immunoassaytechnology/label-free-detection-of-botulinum-neurotoxins-using-a-surface-plasmon-resonance-biosensor

\section{INTECH}

open science | open minds

\section{InTech Europe}

University Campus STeP Ri

Slavka Krautzeka 83/A

51000 Rijeka, Croatia

Phone: +385 (51) 770447

Fax: +385 (51) 686166

www.intechopen.com

\section{InTech China}

Unit 405, Office Block, Hotel Equatorial Shanghai

No.65, Yan An Road (West), Shanghai, 200040, China

中国上海市延安西路65号上海国际贵都大饭店办公楼 405 单元

Phone: +86-21-62489820

Fax: +86-21-62489821 
(C) 2012 The Author(s). Licensee IntechOpen. This is an open access article distributed under the terms of the Creative Commons Attribution 3.0 License, which permits unrestricted use, distribution, and reproduction in any medium, provided the original work is properly cited. 